\title{
ARTICLE
}

Clinical Study

\section{A phase 1, open-label, dose-escalation trial of oral TSR-011 in patients with advanced solid tumours and lymphomas}

\author{
Chia-Chi Lin ${ }^{1}$, Hendrik-Tobias Arkenau ${ }^{2}$, Sharon Lu ${ }^{3}$, Jasgit Sachdev ${ }^{4}$, Javier de Castro Carpeño ${ }^{5}$, Monica Mita ${ }^{6}$, Rafal Dziadziuszko ${ }^{7}$, \\ Wu-Chou Su ${ }^{8}$, Dmitri Bobilev ${ }^{3}$, Lorraine Hughes ${ }^{3}$, Jian Chan $^{3}$, Zhi-Yi Zhang ${ }^{3}$ and Glen J. Weiss ${ }^{9}$
}

BACKGROUND: Anaplastic lymphoma kinase $(A L K)$ gene rearrangements are oncogenic drivers in non-small-cell lung cancer (NSCLC). TSR-011 is a dual ALK and tropomyosin-related kinase (TRK) inhibitor, active against ALK inhibitor resistant tumours in preclinical studies. Here, we report the safety, tolerability and recommended phase 2 dose (RP2D) of TSR-011 in patients with relapsed or refractory $A L K$ - and TRK-positive advanced cancers.

METHODS: In this sequential, open-label, phase 1 trial (NCT02048488), patients received doses of $30 \mathrm{mg}$, escalated to $480 \mathrm{mg}$ every 24 hours (Q24h), followed by an expansion cohort of patients with ALK-positive cancers. The primary objective was to evaluate safety and tolerability. Secondary objectives included pharmacokinetics.

RESULTS: TSR-011 320- and 480-mg Q24h doses exceeded the maximum tolerated dose. At the RP2D of 40 mg every 8 hours (Q8h), the most common grade 3-4 treatment-emergent adverse events occurred in 3.2-6.5\% of patients. Of 14 ALK inhibitor-naive patients with $A L K$-positive NSCLC, 6 experienced partial responses and 8 had stable disease.

CONCLUSIONS: At the RP2D (40 mg Q8h), TSR-011 demonstrated a favourable safety profile with acceptable QTc changes. Limited clinical activity was observed. Based on the competitive ALK inhibitor landscape and benefit/risk considerations, further TSR-011 development was discontinued.

CLINICAL TRIAL REGISTRATION NUMBER: NCT02048488.

British Journal of Cancer (2019) 121:131-138; https://doi.org/10.1038/s41416-019-0503-9

\section{BACKGROUND}

Constitutive activation of anaplastic lymphoma kinase (ALK) stemming from $A L K$ rearrangement is a driving event in a portion of non-small-cell lung cancers (NSCLCs) and several other cancers. Twenty different $A L K$ fusion partner genes have been reported across multiple malignancies. ${ }^{1}$ The uncontrolled activity of ALK fusion proteins results in oncogenic signalling in several downstream pathways that regulate proliferation and malignant transformation. ${ }^{2,3}$ The EML4-ALK translocation detected in NSCLC is a widely recognised $A L K$ fusion gene and is estimated to exist in $5 \%$ of all NSCLC cases worldwide. ${ }^{4}$

ALK inhibitors are highly effective in ALK-positive NSCLC. For example, crizotinib ${ }^{5}$ had better response rates than chemotherapy, with rates of $74 \%$ versus $45 \%$ and a median progression-free survival of 10.9 versus 7.0 months, respectively. ${ }^{6}$

Despite the efficacy of crizotinib, acquired resistance in treated patients is a major hurdle, with disease progression occurring within $\sim 1$ year. ${ }^{6-8}$ Resistance mutations were identified in $20 \%$ of patients with disease progression while participating in a clinical trial. ${ }^{9}$ Resistance mechanisms to crizotinib include $A L K$ amplification; secondary mutations in the $A L K$ kinase domain (e.g. the gatekeeper mutation); mutations that enhance ALK activation (e.g. the F1174L mutation); and activation of bypass signalling pathways (e.g. alterations to EGFR and KIT signalling). ${ }^{10}$ More potent nextgeneration ALK inhibitors (e.g. ceritinib, alectinib, brigatinib and lorlatinib) were developed to overcome resistance mutations ${ }^{11}$ and are approved for advanced ALK-positive NSCLC.

TSR-011 is a potent next-generation ALK inhibitor that also targets tropomyosin-related kinase (TRK) family members (TrkA, TrkB and TrkC). ${ }^{12}$ TRK proteins play a role in the development and maturation of the central and peripheral nervous system, as well as in cell survival. TRK fusion proteins are observed in several cancers, including papillary thyroid carcinoma, colorectal adenocarcinoma, human secretory breast carcinoma and glioblastoma. ${ }^{13}$

TSR-011 has potency at nanomolar concentrations against wildtype $A L K$ in vitro and in ALK-dependent cellular models, as well as in ALK-dependent tumour growth inhibitory activity in mouse models. ${ }^{12,14}$ In addition, TSR-011 is $\sim 200$-fold more potent than crizotinib against the $L 1196 \mathrm{M}$ ALK gatekeeper mutant form and is also about 10-fold more potent than crizotinib against the $R 1275 Q$ mutant, ${ }^{14}$ which is one of the most common activating mutations in neuroblastoma. ${ }^{15}$

\footnotetext{
${ }^{1}$ Department of Oncology, National Taiwan University Hospital, Taipei, Taiwan; ${ }^{2}$ Department of Medical Oncology, Sarah Cannon Research Institute and University College London, London, UK; ${ }^{3}$ Department of Clinical Science, TESARO: A GSK Company, Waltham, MA, USA; ${ }^{4}$ Department of Hematology and Oncology, HonorHealth Research Institute, Scottsdale, AZ, USA; ${ }^{5}$ Department of Oncology, Hospital Universitario La Paz, Madrid, Spain; ${ }^{6}$ Department of Hematology and Oncology, Cedars-Sinai Medical Center, Los Angeles, CA, USA; ${ }^{7}$ Department of Oncology and Radiotherapy, Uniwersyteckie Centrum Kliniczne, Gdansk, Poland; ${ }^{8}$ Department of Hematology and Oncology, National Cheng Kung University Hospital, Tainan, Taiwan and ${ }^{9}$ Department of Medicine, Beth Israel Deaconess Medical Center, Harvard Medical School, Boston, MA, USA Correspondence: Glen J. Weiss (drglenweiss@outlook.com)
}

Received: 20 December 2018 Revised: 14 May 2019 Accepted: 21 May 2019

Published online: 20 June 2019 
This study evaluated the safety, tolerability and pharmacokinetic (PK) profile of TSR-011 in relapsed or refractory locally advanced or metastatic cancer, or cancer for which standard therapy was unavailable.

\section{METHODS}

Study design and treatments

This sequential, open-label, nonrandomised, dose-escalation, phase 1 clinical trial (ClinicalTrials.gov identifier: NCT02048488) evaluated the safety and tolerability of TSR-011 immediate-release (IR) formulation in patients with relapsed or refractory locally advanced or metastatic cancer, or cancer for which standard therapy was unavailable. The study was conducted at 15 sites in Poland, Spain, Taiwan, the United States and the United Kingdom. A formulation sub-study was also undertaken to evaluate a controlled-release (CR) formulation of TSR-011 in a similar patient population.

The primary objective of this trial was to determine the doselimiting toxicity (DLT), maximum tolerated dose (MTD) and recommended phase 2 dose (RP2D) of TSR-011 based on safety, tolerability, PK and exposure-response analyses.

Endpoints included the incidence of DLTs (defined in the 'Safety' section) in the first 28-day treatment cycle (cycle 1), the frequency and severity of adverse events (AEs) and serious AEs (SAEs) and changes in laboratory values, vital signs, physical examination findings and Eastern Cooperative Oncology Group (ECOG) performance status (PS). Plasma concentration and PK parameters for TSR-011 were also investigated.

The starting dose was $30 \mathrm{mg}$, which was determined by review of nonclinical toxicokinetic assessments. A treatment cycle comprised 28 days in the absence of disease progression or unacceptable toxicity. Patients received starting doses ranging from $30 \mathrm{mg}$ once every 24 hours (Q24h) to $480 \mathrm{mg} \mathrm{Q} 24 \mathrm{~h}$, and escalation proceeded based on a $3+3$ design.

The occurrence of DLTs in $>1$ of six patients in a specific dosage cohort (or at a rate of $\geq 33 \%$ if $>6$ patients were in a cohort) indicated that the MTD had been exceeded. The subsequent cohort started at a reduced dosing regimen. Additional dosing schedules were once every 12 hours (Q12h) at 30 and $60 \mathrm{mg}$ and once every 8 hours (Q8h) at 20 and $40 \mathrm{mg}$.

At the end of each 28-day treatment cycle, individual patients within a cohort were eligible for dose escalation (if other criteria were met and judged by the investigator to be medically indicated). Cohort expansion in the case of $>1$ DLT was considered if the DLT could reasonably be considered idiopathic or related to disease progression.

A phase 2a study of the TSR-011 IR formulation was planned to treat $A L K$-positive tumours; however, the study was not initiated when the sponsor terminated further development of TSR-011.

\section{Patients}

Eligible patients were aged $\geq 18$ years (except in countries where the age of majority is 16 years; e.g. the United Kingdom) and had metastatic or locally advanced solid tumours that did not respond to standard therapy or progressed, despite standard therapy, and had either refused standard therapy or standard therapy was unavailable. Patients had an estimated life expectancy of $\geq 3$ months and adequate organ function. In addition, patients had an ECOG $P S \leq 2$. Patients were not required to have measurable disease.

Patients who were pregnant or had leukaemia or uncontrolled congestive heart failure were excluded from the study. A protocol amendment that was implemented before patient enrolment expanded the exclusion criteria to include patients with ongoing cardiac dysrhythmias of National Cancer Institute (NCl) Common Terminology Criteria for Adverse Events (CTCAE) grade $\geq 2$, atrial fibrillation of any grade, corrected QT interval (QTC) $>450 \mathrm{~ms}$ or risk factors for torsade de pointes and those receiving QTcprolonging medicines. In addition, patients had to stop taking prescription, over the counter, or herbal medications known to be inhibitors or inducers of cytochrome P450 (CYP) 3A4 or 3A5.

Further, a protocol amendment was made that required patients (excluding those in the formulation sub-study) to demonstrate that they had ALK- or TRK-positive tumours before enrolment. Mutation status was determined by immunohistochemistry, determination of gene mutations or amplification or analysis of gene rearrangements by fluorescence in situ hybridisation. These assays were performed at local laboratories. A total of 52 patients were enrolled after the protocol amendment implementation (30-mg IR Q12h cohort, $n=5$; 20-mg IR Q8h cohort, $n=16$; 40-mg IR Q8h cohort, $n=31$ ).

This clinical investigation was conducted in compliance with Good Clinical Practice, the Declaration of Helsinki (version 2008) and other applicable regulatory requirements. The protocol was approved by the Institutional Review Board at each participating site, and all patients provided written informed consent before study participation.

\section{PK analysis}

To evaluate PK and establish the RP2D, blood samples were collected from all patients in the phase 1 dose-escalation trial at daily doses of $30-480 \mathrm{mg}$.

A liquid chromatography-tandem mass spectrometry (LC-MS/ MS) method (API 5500, Applied Biosystems, Waltham, MA, USA) using a Gemini C18 column (Phenomenex, Torrance, CA, USA; $50 \times 2.0 \mathrm{~mm}, 3 \mu \mathrm{m})$ for the analysis of TSR-011 in $\mathrm{K}_{2}$ EDTA human plasma was developed and fully validated by Agilux Laboratories (Worcester, MA, USA). Plasma samples were processed through a Biotage (Uppsala, Sweden) ISOLUTE SLE $+200 \mu \mathrm{L}$ of a 96 -wellsupported liquid extraction plate. TSR-011 was determined using electrospray ionisation in positive ion mode, with the multiple reaction monitoring transitions of 578/435 for TSR-011 and 596/453 for TSR-012 as its internal standard. The validated range was $0.87-433.25 \mathrm{nmol} / \mathrm{L}$. The assay interbatch precision, expressed as percent coefficients of variation, ranged from 6.6 to $11.7 \%$, and the interbatch accuracy, expressed as percent bias, ranged from -4.7 to $0.5 \%$.

PK parameters were calculated using noncompartmental analysis (Phoenix WinNonlin version 7.0, Pharsight Corporation, Mountain View, CA, USA).

\section{Safety}

The safety and tolerability of TSR-011 were assessed by evaluating vital signs, physical examination findings, ECOG PS, clinical laboratory testing (serum chemistry, haematology and urinalysis), 12-lead electrocardiograms (ECGs), $\mathrm{AEs}$ and visual history. Toxicities were graded and recorded according to NCI CTCAE version 4.03. Patients were assessed for DLTs during the first 28day cycle. A DLT was defined as any grade $\geq 3$ nonhaematologic toxicity, according to $\mathrm{NCl}$ CTCAE version 4.03 .

\section{Clinical activity}

The overall tumour response in all patients with measurable disease was evaluated, using Response Evaluation Criteria in Solid Tumors, version $1.1{ }^{16}$ completed at times of radiologic assessment at weeks 4 and 8 after dosing and every 8 weeks thereafter. For patients without measurable disease at study entry, radiologic assessment was done as per investigator discretion.

\section{QTc assessments}

We assessed potential effects of TSR-011 with the hERG $\left(K_{\mathrm{Ir}}\right)$ in vitro test system. Inhibition of TSR-011 hERG, via displacement of dofetilide binding, exhibited a half-maximal inhibitory concentration $\left(\mathrm{IC}_{50}\right)$ of $2.3 \mu \mathrm{M}$. A functional assay evaluating TSR-011 confirmed inhibition of the hERG channel, with an $I C_{50}$ value of 
$0.172 \mu \mathrm{M}$. Evaluation of TSR-011 activity against hNav1.5 expressed in HEK-293 cells resulted in an $\mathrm{IC}_{50}$ of $7.6 \mu \mathrm{M}$, and a functional patch-clamp test indicated that the $I_{50}$ for calcium channel inhibition was $>10 \mu \mathrm{M}$.

Potential in vivo effects on the respiratory, central nervous and cardiovascular systems were evaluated in oral dose studies in rats and dogs. A telemetered dog cardiovascular study performed with oral doses of 3,10 and $15 \mathrm{mg} / \mathrm{kg}$ showed a dose-dependent prolongation of the PR interval, a small and dose-dependent increase in QRS duration at 10 and $15 \mathrm{mg} / \mathrm{kg}$ and prolonged QTC at $\geq 3 \mathrm{mg} / \mathrm{kg}$. Increased heart rate was noted at $\geq 3 \mathrm{mg} / \mathrm{kg}$, decreased pulse pressure at $\geq 10 \mathrm{mg} / \mathrm{kg}$ and a mild and transient increase in body temperature at $15 \mathrm{mg} / \mathrm{kg}$. All cardiovascular parameters returned to normal by the subsequent dose, indicating reversibility. TSR-011 did not exhibit any effects in a combined modified Irwin and respiratory safety study in rats at oral doses $\leq 60 \mathrm{mg} / \mathrm{kg}$.

During the phase 1 trial, all patients were monitored by ECGs as part of safety evaluations. The effect of TSR-011 on ECG parameters was evaluated following International Council for Harmonisation of Technical Requirements for Pharmaceuticals for Human Use E14 guidelines. Cardiac function (QT, Bazett-corrected QT formula, Fridericia-corrected QT formula [QTcF], PR, QRS, RR and heart rate) was evaluated by a 12-lead ECG with triplicate readouts at scheduled time points, along with changes from baseline to each scheduled time point.

The TSR-011 CR formulation was evaluated in an open-label sub-study. Each patient received a single 30 -mg CR dose of TSR011 , administered orally on day 1 . The cohort could be expanded to six patients $(3+3)$ if the CR formulation had a desirable PK profile compared with the IR formulation (i.e. attenuation of maximum plasma concentration $\left[C_{\max }\right]$ and maintenance of exposure and lowest plasma trough concentration $\left.\left[C_{\text {trough }}\right]\right)$. This sub-study was terminated after evaluation of PK from four patients, who subsequently rolled over into the main study for continued treatment.

PK samples, collected before dosing and at $0.5,1,2,4,8,12,18$, $24,32,44,48,72,96$ and $120 \mathrm{~h}$ after dosing, were analysed as above, using the LC-MS/MS method. Nonparametric superposition modelling (Phoenix WinNonlin software, Pharsight Corporation) based on the PK of TSR-011 30-mg CR was undertaken to project a daily $\mathrm{CR}$ tablet strength matching the current clinical exposure of $40 \mathrm{mg}$ three times daily (TID; Q8h).

Statistical analysis

Analyses were descriptive in nature. No formal statistical tests were performed. Summary tabulations included the number of observations; mean, standard deviation, median, minimum and maximum for continuous variables; and number and percentage per category for categorical data. Percentages were based on the number of patients with available values, unless specified otherwise.

The analysis sets included a safety population comprising all patients who received $\geq 1$ dose of study drug; a PK population comprising all patients who received $\geq 1$ dose of study drug and had measurable drug concentrations; and a clinical activity population comprising all patients who received $\geq 1$ dose of study drug and had $\geq 1$ post-baseline assessment of clinical activity. An additional analysis was performed on patients who met the criteria of achieving $\geq 90 \%$ study drug compliance during the first treatment cycle.

\section{RESULTS}

\section{Study populations}

Over a duration of 4 years, 82 patients were screened and 72 were enrolled and treated in the phase 1 main study. Sixteen patients received varying doses of TSR-011, ranging from 30 to $480 \mathrm{mg}$
Q24h. After grade 3 QTc prolongation was observed at doses above $320 \mathrm{mg}$ Q24h, fractional dosing was explored to circumvent such AEs. A total of 56 patients were enrolled into fractional IR dose regimen cohorts (30 mg Q12h, $n=6 ; 60 \mathrm{mg} \mathrm{Q12h,} n=3$; $20 \mathrm{mg}$ Q8h, $n=16 ; 40 \mathrm{mg}$ Q8h, $n=31$, Fig. S1).

An additional four patients were enrolled in the formulation sub-study; all were subsequently rolled over into the main study and treated with 40-mg IR Q8h after completion of cycle 1.

Overall, 65 patients $(90.3 \%)$ discontinued the study. The most frequent reason for discontinuation was disease progression (46 patients [63.9\%]). The other 19 patients discontinued because of an $\mathrm{AE}(n=3)$, death $(n=4)$, physician decision $(n=8)$, or decline in clinical status, loss to follow-up, patient inability to attend the final study visit or withdrawal by the patient ( $n=1$ each).

\section{Baseline characteristics}

Patient demographics and baseline characteristics are summarised in Table 1. The mean age of enrolled patients in the main study was 56.9 years (range, 21-87 years). Most patients were female (56.9\%), white $(68.1 \%)$ and had an ECOG PS of $0(36.1 \%)$ or 1 (59.7\%). Of 72 patients enrolled, 56 (77.8\%) were ALK inhibitor treatment naive and 41 (56.9\%) were $A L K$ positive.

\section{Safety and tolerability}

Overall, patients remained on treatment for a median of 112 days (range, 4-848 days), and $48.6 \%$ of patients remained in the study for 2-5 cycles, with 28 days per cycle.

A total of 70 patients $(97.2 \%)$ in the safety population experienced $\geq 1$ treatment-emergent $A E$ (TEAE), as summarised in Table 2. The most frequently reported TEAEs by class, regardless of causality, were gastrointestinal disorders (44 patients [61.1\%]), followed by general disorders and administration-site conditions (fatigue, asthenia, disease progression and peripheral oedema; 36 patients [50.0\%]). Individual TEAEs reported in $>15 \%$ of patients included constipation and fatigue (14 patients [19.4\%] each); diarrhoea, vomiting and QTc prolongation (13 patients [18.1\%] each); and asthenia, headache, decreased appetite and anaemia (11 patients [15.3\%] each).

Most TEAEs (64\% of events) were grade 1 in severity. However, grade 3 TEAEs were reported in 37 patients (51.4\%; specific grade 3 events reported in $>1$ patient are shown in Table 3 ). One patient experienced a grade 4 TEAE of anaemia.

Study drug-related TEAEs occurred in 40 patients (55.6\%). The most commonly reported study drug-related TEAEs were QTC prolongation, constipation, decreased appetite, vomiting and fatigue (Table 4). One patient (1.4\%) experienced a study drugrelated $S A E$.

Treatment-emergent SAEs occurred in 28 patients (38.9\%) (Table 5). The most frequent SAE among patients with $\geq 1$ treatment-emergent SAE was disease progression, which occurred in six patients (8.3\%). All treatment-emergent SAEs were considered by the investigator as unrelated or unlikely to be related to the study drug, except for anaemia in one patient that was considered related to the study drug.

Overall, 12 TEAEs led to study drug discontinuation in 11 patients (15.3\%). Of these, ECG QTc prolongation (two patients) and pneumonitis (one patient) were considered related to the study drug. Six patients died because of TEAEs, including disease progression $(n=5)$ and subarachnoid haemorrhage, not related to the study drug $(n=1)$. In addition, one patient died due to cardiopulmonary failure before receiving the study drug.

During dose escalation, none of the patients experienced DLTs in the 30-, 60-, 120- and 240-mg IR Q24h cohorts. Grade 3 QTc prolongation occurred in two of four patients in the 480-mg Q24h cohort. Hence, the dose was de-escalated to $320 \mathrm{mg}$ Q24h. One patient in this cohort experienced grade 3 ECG QTC prolongation within the DLT period, and an additional patient in this cohort was 
Table 1. Demographics and baseline characteristics (safety population)

\begin{tabular}{|c|c|c|c|}
\hline & \multicolumn{3}{|c|}{ TSR-011 IR formulation } \\
\hline & $\begin{array}{l}20 \mathrm{mg} \text { Q8h } \\
(n=16)\end{array}$ & $\begin{array}{l}40 \mathrm{mg} \text { Q8h } \\
(n=31)\end{array}$ & $\begin{array}{l}\text { All patients } \\
(N=72)\end{array}$ \\
\hline \multicolumn{4}{|l|}{ Age, years } \\
\hline Mean (SD) & $54.9(9.64)$ & $51.7(13.78)$ & $56.9(13.44)$ \\
\hline Median & 53.5 & 51 & 58 \\
\hline Min-max & $36-68$ & $21-77$ & $21-87$ \\
\hline \multicolumn{4}{|l|}{ Sex, $n(\%)$} \\
\hline Male & $8(50.0)$ & $16(51.6)$ & $31(43.1)$ \\
\hline Female & $8(50.0)$ & $15(48.4)$ & $41(56.9)$ \\
\hline \multicolumn{4}{|l|}{ Race, $n(\%)$} \\
\hline Asian & $5(31.3)$ & $13(41.9)$ & $20(27.8)$ \\
\hline $\begin{array}{l}\text { Black or African } \\
\text { American }\end{array}$ & 0 & $1(3.2)$ & $1(1.4)$ \\
\hline White & $10(62.5)$ & $17(54.8)$ & $49(68.1)$ \\
\hline Unknown & $1(6.3)$ & 0 & $2(2.8)$ \\
\hline \multicolumn{4}{|c|}{ Smoking history, $n$ (\%) } \\
\hline Former & $8(50.0)$ & $15(48.4)$ & $32(44.4)$ \\
\hline Never & $8(50.0)$ & $16(51.6)$ & $40(55.6)$ \\
\hline \multicolumn{4}{|c|}{ ECOG performance status, $n(\%)$} \\
\hline 0 & $5(31.3)$ & $13(41.9)$ & $26(36.1)$ \\
\hline 1 & $10(62.5)$ & $17(54.8)$ & $43(59.7)$ \\
\hline 2 & 0 & $1(3.2)$ & $2(2.8)$ \\
\hline 3 & $1(6.3)$ & 0 & $1(1.4)$ \\
\hline \multicolumn{4}{|c|}{ Prior ALK inhibitor treatment, $n$ (\%) } \\
\hline$Y_{e s}{ }^{a}$ & $7(43.8)$ & $8(25.8)$ & $16(22.2)$ \\
\hline Crizotinib & $6(37.5)$ & $6(19.4)$ & $12(16.7)$ \\
\hline Ceritinib & 0 & $3(9.7)$ & $3(4.2)$ \\
\hline Alectinib & $1(6.3)$ & $1(3.2)$ & $2(2.8)$ \\
\hline No & $9(56.3)$ & $23(74.2)$ & $56(77.8)$ \\
\hline \multicolumn{4}{|c|}{ ALK-positive mutation status, ${ }^{\mathrm{b}}$ n (\%) } \\
\hline Yes & $10^{c}(62.5)$ & $24^{d}(77.4)$ & $41(56.9)$ \\
\hline No & $2(12.5)$ & $4(12.9)$ & $11(15.3)$ \\
\hline Not done & $4(25.0)$ & $3(9.7)$ & $20(27.8)$ \\
\hline \multicolumn{4}{|c|}{ TRK-positive mutation status, $n$ (\%) } \\
\hline Yes & $6(37.5)$ & $3(9.7)$ & $11(15.3)$ \\
\hline No & $6(37.5)$ & $28(90.3)$ & $48(66.7)$ \\
\hline Not done & $4(25.0)$ & 0 & $13(18.1)$ \\
\hline \multicolumn{4}{|c|}{$\begin{array}{l}\text { ALK anaplastic lymphoma kinase, ECOG Eastern Cooperative Oncology } \\
\text { Group, IR immediate release, max maximum, min minimum, Q8h once } \\
\text { every } 8 \text { hours, SD standard deviation, TRK tropomyosin-related kinase } \\
\text { a Three patients received two ALK inhibitors } \\
{ }^{b} \text { Included gene mutations, amplifications or rearrangements } \\
{ }^{c} \text { Three patients were ALK inhibitor naive } \\
{ }^{d} \text { Seventeen patients were ALK inhibitor naive }\end{array}$} \\
\hline
\end{tabular}

retrospectively determined to have experienced grade 3 QTC prolongation.

It was hypothesised that QTc prolongation is related to $C_{\max }$, so fractionated dosing was implemented to circumvent QTc prolongation while maintaining the drug trough level. Evaluated cohorts included $30 \mathrm{mg} \mathrm{Q12h,} 20 \mathrm{mg}$ Q8h, $60 \mathrm{mg} \mathrm{Q12h}$ and $40 \mathrm{mg}$ Q8h. Based on the evaluation of QTc prolongations and PK profiles (discussed in the following sections), 40-mg IR TID (Q8h) was determined to be the RP2D.
Table 2. Overall TEAEs in all patients of the phase 1 main study and two fractional dose treatment groups

\begin{tabular}{|c|c|c|c|}
\hline & \multicolumn{3}{|c|}{ TSR-011 IR formulation } \\
\hline & $\begin{array}{l}20 \mathrm{mg} \mathrm{Q} 8 \mathrm{~h} \\
(n=16)\end{array}$ & $\begin{array}{l}40 \mathrm{mg} \text { Q8h } \\
(n=31)\end{array}$ & $\begin{array}{l}\text { All patients } \\
(N=72)\end{array}$ \\
\hline Total number of TEAEs ${ }^{a}$ & 159 & 167 & 621 \\
\hline \multicolumn{4}{|c|}{ Number (\%) of patients with } \\
\hline Any TEAE & $16(100.0)$ & $29(93.5)$ & $70(97.2)$ \\
\hline Any serious TEAE & $7(43.8)$ & $12(38.7)$ & $28(38.9)$ \\
\hline $\begin{array}{l}\text { Any study drug- } \\
\text { related TEAE }\end{array}$ & $9(56.3)$ & $13(41.9)$ & $40(55.6)$ \\
\hline $\begin{array}{l}\text { Any TEAE leading to } \\
\text { treatment } \\
\text { discontinuation }\end{array}$ & $2(12.5)$ & $5(16.1)$ & $11(15.3)$ \\
\hline $\begin{array}{l}\text { Any AE leading to } \\
\text { death }^{\mathrm{b}}\end{array}$ & $2(12.5)$ & $2(6.5)$ & $6(8.3)$ \\
\hline \multicolumn{4}{|c|}{ 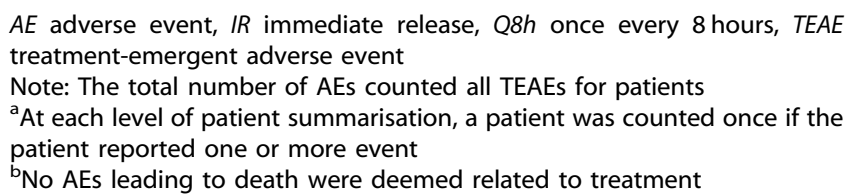 } \\
\hline
\end{tabular}

Table 3. Grade 3 treatment-emergent adverse events reported by more than one patient in the Q8h cohorts compared with the safety population

\begin{tabular}{|c|c|c|c|}
\hline \multirow[t]{2}{*}{ Preferred term } & \multicolumn{3}{|c|}{ TSR-011 IR formulation, $n(\%)$} \\
\hline & $\begin{array}{l}20 \mathrm{mg} \text { Q8h } \\
(n=16)\end{array}$ & $\begin{array}{l}40 \mathrm{mg} \text { Q8h } \\
(n=31)\end{array}$ & $\begin{array}{l}\text { All patients } \\
(N=72)\end{array}$ \\
\hline Anaemia & $2(12.5)$ & $2(6.5)$ & $5(6.9)$ \\
\hline $\begin{array}{l}\text { Electrocardiogram QTC } \\
\text { prolonged }\end{array}$ & 0 & $1(3.2)$ & $4(5.6)$ \\
\hline Asthenia & $1(6.3)$ & $1(3.2)$ & $3(4.2)$ \\
\hline Dyspnoea & 0 & 0 & $3(4.2)$ \\
\hline Ascites & $1(6.3)$ & 0 & $2(2.8)$ \\
\hline Fatigue & $1(6.3)$ & 0 & $2(2.8)$ \\
\hline $\begin{array}{l}\text { Metastases to the central } \\
\text { nervous system }\end{array}$ & $1(6.3)$ & $1(3.2)$ & $2(2.8)$ \\
\hline \multicolumn{4}{|c|}{$\begin{array}{l}\text { IR immediate release, Q8h once every } 8 \text { hours, QTC corrected QT } \\
\text { Note: Adverse events were coded using the Medical Dictionary for } \\
\text { Regulatory Activities, version 18.0. If the severity of an adverse event was } \\
\text { missing, the adverse event was reported as "severe" }\end{array}$} \\
\hline
\end{tabular}

PK results

Plasma concentration-time profiles (Fig. 1) for both cycle 1/day 1 and cycle 2, day 1/day 29 of TSR- 011 were characterised by rapid absorption, with median time to $C_{\max }\left(t_{\max }\right)$ occurring $2-4 \mathrm{~h}$ after a single oral dose at cycle 1. Following attainment of $C_{\text {max }}$, TSR-011 concentrations declined biexponentially. Plasma concentration profiles were comparable across all cohorts, as well as with repeat dosing for 29 days. The half-life ranged from 7 to $27 \mathrm{~h}$, with apparent clearance and apparent volume of distribution of 9.62-46.60 L/h and 188-1620 L, respectively. Systemic exposure increased supraproportionally, with a $41-$ and 42 -fold increase in geometric mean $C_{\max }$ and area under the concentration-time curve (AUC) from 0 to $24 \mathrm{~h}$, respectively, over the 16 -fold increase in TSR-011 dose (range, 30-480 mg). 
Table 4. Drug-related treatment-emergent adverse events reported by more than one patient in the Q8h cohorts compared with the safety population

\begin{tabular}{|c|c|c|c|}
\hline \multirow[t]{2}{*}{ Preferred term } & \multicolumn{3}{|c|}{ TSR-011 IR formulation, $n(\%)$} \\
\hline & $\begin{array}{l}20 \mathrm{mg} \text { Q8h } \\
(n=16)\end{array}$ & $\begin{array}{l}40 \mathrm{mg} \text { Q8h } \\
(n=31)\end{array}$ & $\begin{array}{l}\text { All patients } \\
(N=72)\end{array}$ \\
\hline $\begin{array}{l}\text { Electrocardiogram QTC } \\
\text { prolonged }\end{array}$ & $1(6.3)$ & $3(9.7)$ & $12(16.7)$ \\
\hline Constipation & $2(12.5)$ & $2(6.5)$ & $5(6.9)$ \\
\hline Decreased appetite & $1(6.3)$ & 0 & $4(5.6)$ \\
\hline Vomiting & $2(12.5)$ & $1(3.2)$ & $4(5.6)$ \\
\hline Fatigue & $1(6.3)$ & 0 & $4(5.6)$ \\
\hline Diarrhoea & $1(6.3)$ & 0 & $3(4.2)$ \\
\hline Dysgeusia & 0 & 0 & $3(4.2)$ \\
\hline Nausea & 0 & $1(3.2)$ & $3(4.2)$ \\
\hline Peripheral oedema & 0 & $1(3.2)$ & $3(4.2)$ \\
\hline Headache & 0 & 0 & $3(4.2)$ \\
\hline Abnormal dreams & $1(6.3)$ & 0 & $2(2.8)$ \\
\hline Anaemia & 0 & $1(3.2)$ & $2(2.8)$ \\
\hline Asthenia & $1(6.3)$ & 0 & $2(2.8)$ \\
\hline Dysaesthesia & $1(6.3)$ & 0 & $2(2.8)$ \\
\hline Hot flush & $1(6.3)$ & 0 & $2(2.8)$ \\
\hline Insomnia & 0 & $2(6.5)$ & $2(2.8)$ \\
\hline Myalgia & 0 & 0 & $2(2.8)$ \\
\hline Rash & 0 & $1(3.2)$ & $2(2.8)$ \\
\hline Increased transaminases & 0 & 0 & $2(2.8)$ \\
\hline
\end{tabular}

IR immediate release, Q8h once every 8 hours, QTc corrected QT interval Note: At each level of patient summarisation, a patient was counted once if the patient reported one or more event. Adverse events were coded using the Medical Dictionary for Regulatory Activities, version 18.0

Following daily oral administration of TSR-011 (80-480 mg) at cycle 2 /day 1 , the median $t_{\max }$ was achieved between 2.00 and $6.00 \mathrm{~h}$, with $C_{\max }$ ranging from 447.11 to $3327.36 \mathrm{nmol} / \mathrm{L}$. Apparent clearance and apparent volume of distribution ranged from 9.26 to $29.10 \mathrm{~L} / \mathrm{h}$ and 206 to $408 \mathrm{~L}$, respectively.

Systemic exposure at steady state increased sub-proportionally with increasing doses, with a 3.3- and 2.9-fold increase in exposure for $C_{\max }$ and $A U C$ from time 0 to the last measurable concentration, respectively, over the sixfold increase in dose (range, $80-480 \mathrm{mg}$ ). The accumulation ratio, where calculable, ranged from 0.68 to 5.24 .

QTc prolongation, mitigation strategy and RP2D

QTc prolongation was observed during dose escalation and was the key determinant of the MTD. The relationship between TSR011 plasma concentration and change from baseline in QTcF $(\triangle \mathrm{QTCF})$ was explored using linear regression with prediction intervals (Fig. 1c, solid black lines). All the $\triangle \mathrm{QTCF}$ data with matching drug concentration values were used for the analysis. The correlation was positive and significant (i.e. slope of 0.02358 [red solid line]; 95\% confidence interval [Cl], 0.01970-0.02747 [red dotted line]; $P<0.0001)$, indicating that QTc prolongation was drug related.

The mean $\triangle Q T C F$ appeared to be dose dependent (Fig. 1d). All the available $\triangle \mathrm{QTCF}$ data from each patient were included in the analysis. Once-daily (QD) doses at $240 \mathrm{mg}(n=3), 320 \mathrm{mg}(n=3)$ and $480 \mathrm{mg}(n=4)$ corresponded to a $\Delta \mathrm{QTCF}$ of $>20 \mathrm{~ms}$ (a substantial risk for proarrhythmic disorders, including torsade de pointes). The mean $\Delta$ QTcF for $120 \mathrm{mg}$ QD $(n=1)$ was $19 \mathrm{~ms}$, with the upper bound of the two-sided $90 \% \mathrm{Cl}$ at $27 \mathrm{~ms}$. The data
Table 5. Treatment-emergent SAEs reported by more than one patient by system organ class and the preferred term (safety population)

\begin{tabular}{|c|c|c|c|}
\hline \multirow[t]{2}{*}{ Preferred term } & \multicolumn{3}{|c|}{ TSR-011 IR formulation } \\
\hline & $\begin{array}{l}20 \mathrm{mg} \text { Q8h } \\
(n=16)\end{array}$ & $\begin{array}{l}40 \mathrm{mg} \mathrm{Q} Q \mathrm{~h} \\
(n=31)\end{array}$ & $\begin{array}{l}\text { All patients } \\
(N=72)\end{array}$ \\
\hline $\begin{array}{l}\text { Total number of treatment-emergent } \\
\mathrm{SAEs}^{\mathrm{a}}\end{array}$ & 14 & 16 & 49 \\
\hline $\begin{array}{l}\text { Patients with } \geq 1 \text { treatment-emergent } \\
\text { SAE, } n(\%)^{b}\end{array}$ & $7(43.8)$ & $12(38.7)$ & $28(38.9)$ \\
\hline Nervous system disorders, $n(\%)$ & $1(6.3)$ & $2(6.5)$ & $8(11.1)$ \\
\hline Mental impairment, $n$ (\%) & $1(6.3)$ & 0 & $2(2.8)$ \\
\hline Seizure & $1(6.3)$ & $1(3.2)$ & $2(2.8)$ \\
\hline Subarachnoid haemorrhage & 0 & $1(3.2)$ & $1(1.4)$ \\
\hline $\begin{array}{l}\text { General disorders and } \\
\text { administration-site conditions, } n(\%)\end{array}$ & $2(12.5)$ & $2(6.5)$ & $7(9.7)$ \\
\hline Disease progression & $2(12.5)$ & $2(6.5)$ & $6(8.3)$ \\
\hline Asthenia & $1(6.3)$ & 0 & $1(1.4)$ \\
\hline Gastrointestinal disorders, $n$ (\%) & $1(6.3)$ & $1(3.2)$ & $5(6.9)$ \\
\hline Abdominal pain & 0 & $1(3.2)$ & $1(1.4)$ \\
\hline Gastric haemorrhage & $1(6.3)$ & 0 & $1(1.4)$ \\
\hline Infections and infestations, $n$ (\%) & $1(6.3)$ & $4(12.9)$ & $5(6.9)$ \\
\hline Gastric ulcer helicobacter & 0 & $1(3.2)$ & $1(1.4)$ \\
\hline Infection & 0 & $1(3.2)$ & $1(1.4)$ \\
\hline Lower respiratory tract infection & 0 & $1(3.2)$ & $1(1.4)$ \\
\hline Mastoiditis & $1(6.3)$ & 0 & $1(1.4)$ \\
\hline Pneumonia & 0 & $1(3.2)$ & $1(1.4)$ \\
\hline $\begin{array}{l}\text { Respiratory, thoracic and mediastinal } \\
\text { disorders, } n(\%)\end{array}$ & 0 & $1(3.2)$ & $4(5.6)$ \\
\hline Dyspnoea & 0 & 0 & $3(4.2)$ \\
\hline Pleural effusion & 0 & $1(3.2)$ & $1(1.4)$ \\
\hline $\begin{array}{l}\text { Neoplasms benign, malignant and } \\
\text { unspecified (including cysts and } \\
\text { polyps), } n \text { (\%) }\end{array}$ & $2(12.5)$ & $1(3.2)$ & $3(4.2)$ \\
\hline $\begin{array}{l}\text { Metastases to the central nervous } \\
\text { system, } n(\%)\end{array}$ & $1(6.3)$ & $1(3.2)$ & $2(2.8)$ \\
\hline Basal cell carcinoma & $1(6.3)$ & 0 & $1(1.4)$ \\
\hline $\begin{array}{l}\text { Blood and lymphatic system } \\
\text { disorders, } n(\%)\end{array}$ & 0 & $2(6.5)$ & $2(2.8)$ \\
\hline Anaemia & 0 & $2(6.5)$ & $2(2.8)$ \\
\hline Cardiac disorders & 0 & $1(3.2)$ & $1(1.4)$ \\
\hline Pericardial effusion & 0 & $1(3.2)$ & $1(1.4)$ \\
\hline Hepatobiliary disorders, $n(\%)$ & $1(6.3)$ & 0 & $1(1.4)$ \\
\hline Portal vein thrombosis & $1(6.3)$ & 0 & $1(1.4)$ \\
\hline $\begin{array}{l}\text { Metabolism and nutrition disorders, } \\
n(\%)\end{array}$ & $1(6.3)$ & 0 & $1(1.4)$ \\
\hline Dehydration & $1(6.3)$ & 0 & $1(1.4)$ \\
\hline $\begin{array}{l}\text { Musculoskeletal and connective } \\
\text { tissue disorders, } n(\%)\end{array}$ & $1(6.3)$ & 0 & $1(1.4)$ \\
\hline Bone pain & $1(6.3)$ & 0 & $1(1.4)$ \\
\hline Vascular disorders, $n(\%)$ & $1(6.3)$ & 0 & $1(1.4)$ \\
\hline Deep-vein thrombosis & $1(6.3)$ & 0 & $1(1.4)$ \\
\hline \multicolumn{4}{|c|}{$\begin{array}{l}A E \text { adverse event, IR immediate release, Q8h once every } 8 \text { hours, SAE } \\
\text { serious adverse event } \\
\text { Note: AEs were coded using the Medical Dictionary for Regulatory Activities, } \\
\text { version } 18.0 \\
\text { aThe total number of treatment-emergent SAEs counts all treatment- } \\
\text { emergent SAEs for patients } \\
{ }^{b} \text { At each level of patient summarisation, a patient was counted once if the } \\
\text { patient reported one or more event }\end{array}$} \\
\hline
\end{tabular}

from one patient in the 30-mg QD cohort were considered to be outlying. This patient was taking concomitant ondansetron, which has been associated with QTC prolongation. Therefore, the observed QTc prolongation may not be related to TSR-011 at this dose level.

Fractionated dosing was implemented to reduce potential QTc prolongation. Both twice-daily (BID; Q12h) and TID (Q8h) dosing 

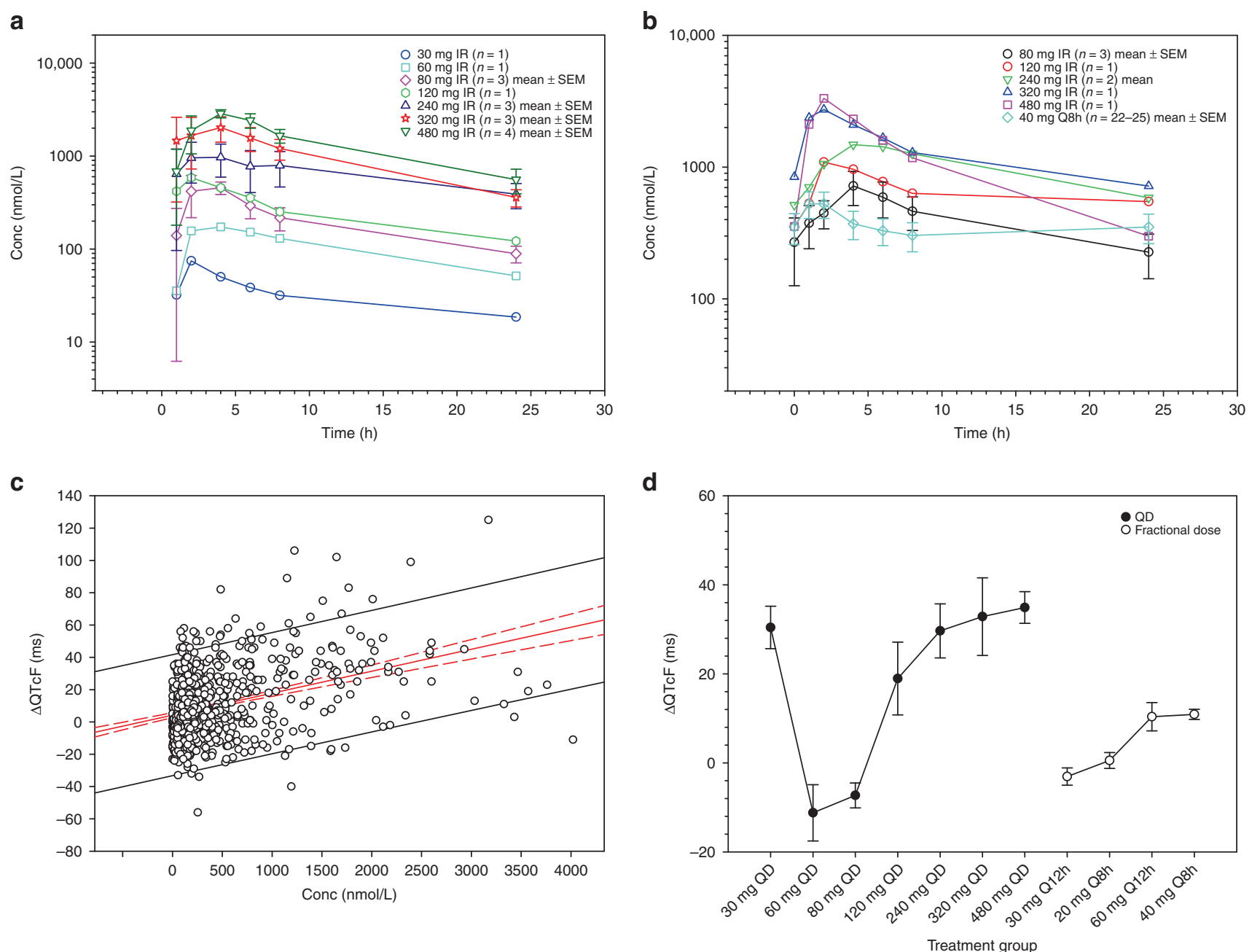

Fig. 1 Mean \pm SEM plasma concentration-time profiles (semi-log) of TSR-011 following single oral daily doses in patients with cancer. a Cycle $1 /$ day 1 . b Cycle $2 /$ day 1 . Summary of $\Delta \mathrm{QTCF}$ by plasma concentration and dose. c PK concentration-response (PK-QT) relationship from all dose groups (30 mg QD, $60 \mathrm{mg}$ QD, $80 \mathrm{mg}$ QD, $120 \mathrm{mg}$ QD, $240 \mathrm{mg}$ QD, $320 \mathrm{mg}$ QD, $480 \mathrm{mg}$ QD, $30 \mathrm{mg} \mathrm{Q12h,} 20 \mathrm{mg} \mathrm{Q8h,60} \mathrm{mg} \mathrm{Q12h,} 40 \mathrm{mg}$ $\mathrm{Q} 8 \mathrm{~h}$ and $30 \mathrm{mg} \mathrm{QD}$ controlled release). d Plot of dose and regimen versus mean $\triangle \mathrm{QTCF}$ (ms) from baseline with $90 \% \mathrm{Cl}$. $\triangle Q T c F$ change in Fridericia-corrected QT interval, CI confidence interval, Conc concentration, $I R$ immediate release, $P K$ pharmacokinetics, Q8h once every 8 hours, Q12h once every 12 hours, QD once daily, SEM standard error of the mean

regimens were explored at cumulative daily doses of 60 and 120 mg (Fig. 1d). This strategy maintained mean $\triangle \mathrm{QTCF}$ below $20 \mathrm{~ms}$ for all four dose regimens. The highest mean $\triangle \mathrm{QTCF}$ of $11 \mathrm{~ms}(90 \%$ $\mathrm{Cl}, 9.75-12.00 \mathrm{~ms})$ was observed in the 40-mg TID cohort $(n=27)$. While no specific guidance exists, it is generally considered acceptable to conclude that a change in QTc from baseline is not clinically meaningful, if the upper bound of the two-sided $90 \% \mathrm{Cl}$ for the $\triangle Q T c F$ is $<20 \mathrm{~ms}$. At $40-\mathrm{mg}$ TID dosing, there was one observed grade 3 TEAE of QTc prolongation. The dose of $40 \mathrm{mg}$ TID (Q8h) was determined to be the RP2D; dose escalation was stopped.

\section{CR formulation}

Rationale for a switch from IR to $C R$. Fractionated dosing (Q8h) was successful in minimising the ratio of $C_{\max }$ to $C_{\text {trough }}$ while maintaining the required drug trough level. At the 120-mg QD dose (day 29 of steady state, $n=1$ ), this ratio was $\sim 2.00$. It was reduced to $\sim 1.42$ (day 29 of steady state, $n=25$ ) with the $40-\mathrm{mg}$ TID (Q8h) dose, which was equivalent to a 120-mg cumulative daily dose. At this dosage and regimen, the overall steady-state PK profile (day $29, n=22-25$ ) exhibited high interpatient variability, with percent coefficients of variation ranging from 108 to $132 \%$ and a mean $C_{\max }$ and $C_{\text {trough }}$ of 528.41 and $351.38 \mathrm{nmol} / \mathrm{L}$, respectively. The $\mathrm{PK}$ profiles were also evaluated using the fluctuation index, defined as $\left(C_{\max }-C_{\text {trough }}\right) / C_{\text {avg, }}$ and swing percentage, defined as $\left(C_{\max }-C_{\text {trough }}\right) / C_{\text {trough }} \times 100$, with ranges of $0.25-1.60$ and $28.8-295.0 \%$, respectively. The CR formulation was under development to mimic the PK profile of $40 \mathrm{mg}$ TID, with the potential to generate a more continuous effect through compliance with the daily dosage routine and maintenance of therapeutic plasma concentrations. Less fluctuation and swing are desirable in a CR formulation through reduced intrapatient variability. The criteria set for the new formulation were such that the mean $C_{\text {max }} / C_{\text {trough }}$ ratio should be maintained within 2.00, with a $C_{\text {trough }}$ of about $351.38 \mathrm{nmol} / \mathrm{L}$. No observed concentration should be higher than $2599.50 \mathrm{nmol} / \mathrm{L}$, which was the highest concentration observed in the 40-mg IR TID cohort.

$P K$ of $C R$ formulation. A CR formulation was subsequently developed to mimic the PK profile of the 40-mg TID (Q8h) dose, including the mean $C_{\text {trough. }}$. PK parameters were measured in a cohort of four patients who received a $30-\mathrm{mg} C R$ formulation. The mean $C_{\max }$ was $37.95 \mathrm{nmol} / \mathrm{L}$, and $t_{\max }$ occurred $\sim 4 \mathrm{~h}$ after dosing. Based on nonparametric superposition modelling, consistent with fractionated dosing, the ratio of mean $\mathrm{C}_{\max }$ to mean $C_{\text {trough }}$ was maintained at about 1.65 of steady state with 
daily dosing. In addition, based on the $30-\mathrm{mg}$ CR prototype, a 240-mg CR daily dose was projected to match the clinical exposure of $40 \mathrm{mg}$ TID (Q8h). The trough level for the 240-mg CR prototype was about $415.92 \mathrm{nmol} / \mathrm{L}$, which matches the trough of $40 \mathrm{mg}$ TID (Q8h) at a mean of $351.38 \mathrm{nmol} / \mathrm{L}$. The mean $\mathrm{C}_{\max }$ was projected to be $<693.20 \mathrm{nmol} / \mathrm{L}$. Based on the linear regression (Fig. 1c), at $693.20 \mathrm{nmol} / \mathrm{L}$, the mean $\Delta \mathrm{QTCF}$ with $95 \% \mathrm{Cl}$ ranged from 10.6 to $16.7 \mathrm{~ms}$, which is within the manageable risk of QTc prolongation.

\section{Efficacy}

While tumour response data were collected from 66 patients, here, we present response data only for patients with $A L K$ positive tumour samples $(n=22)$ receiving the RP2D $(40 \mathrm{mg}$ Q8h). Fourteen of these patients were ALK inhibitor naive, and eight had been previously treated with an ALK inhibitor. No ALKpositive patient had a complete response; seven patients had a partial response (six confirmed, one unconfirmed) and 14 had stable disease. Among ALK inhibitor-naive patients, six had partial responses (five confirmed, one unconfirmed) and eight had stable disease (Table S1). The median duration of treatment was 112 days (range, $4-848$ days), and $47 \%$ of patients remained in the study for 2-5 cycles. Three $A L K$-positive patients are continuing in the study and receiving the study drug as of the time of the study report. A patient with a neuroblastoma harbouring an ALK mutation (R1275Q) did not respond to TSR011 treatment.

\section{DISCUSSION}

The PK and safety of TSR-011 were studied in this sequential, open-label, nonrandomised, dose-escalation, phase 1 clinical trial at doses ranging from 20 to $480 \mathrm{mg}$ administered to patients with relapsed or refractory locally advanced or metastatic cancer. The 320- and 480-mg Q24h doses exceeded the MTD. Patients in these cohorts experienced grade 3 ECG QTc prolongation. Fractional dosing in subsequent cohorts resulted in an RP2D of $40 \mathrm{mg}$ TID (Q8h).

Safety data show that the RP2D was generally well tolerated, with an acceptable and manageable AE profile. Compared with AEs of grade $\geq 3$ severity reported with the use of alectinib or brigatinib, ${ }^{17,18}$ no grade $\geq 3$ pneumonitis or hypoxia was observed in patients treated with TSR-011 (40 mg TID). Longer-term treatment of patients at this dosage suggested that most could continue treatment with dose interruptions or dose reductions to manage TEAEs.

At the 40-mg TID (Q8h) RP2D ( $n=27$, QTc-evaluable patients), the frequency of drug-related QTc prolongation was lower compared with the overall safety population $(9.7 \%$ vs $16.7 \%$, respectively). One in 27 patients (3.7\%) had a $\Delta Q T c$ of $>60 \mathrm{~ms}$ and a QTc > $500 \mathrm{~ms}$ (a grade 3 event). Clinical trials of ceritinib showed that, among 919 patients, $6 \%$ had a $\Delta Q T c$ of $>60 \mathrm{~ms}$ and $1.3 \%$ had a QTc $>500 \mathrm{~ms}^{19}$ In clinical trials of alectinib and brigatinib, QTC was not prolonged to any clinically relevant extent. ${ }^{17,18}$

PK analyses showed that after single-dose administration of TSR-011, systemic exposure $C_{\max }$ and AUC values increased supraproportionally over the $30-$ to $480-\mathrm{mg}$ dose range. Profiling of the CYPs responsible for metabolism of TSR-011 was conducted, using a panel of recombinant CYP enzymes and liver microsomes. The results indicated that CYP3A4 is responsible for the majority of CYP-dependent metabolism of TSR-011, with minor amounts of metabolism by other enzymes, including CYP2D6, CYP2C9, and CYP1A. Meanwhile, TSR-011 inhibited CYP3A4 and CYP2D6 in human liver microsomes, with an $\mathrm{IC}_{50}$ of 23.3 and $32.9 \mu \mathrm{M}$, respectively, which may provide a rationale for the supraproportional systemic exposure observed after administration of a single dose. After repeated dosing, systemic exposure at steady state increased in a sub-proportional manner over the dose range of $80-480 \mathrm{mg}$. TSR-011 is a substrate of efflux transporters with a $P_{a p p}(B-A) /(A-B)$ ratio of 7.7. It is speculated that with repeated dosing, TSR-011 may induce the transporters as well as CYP enzymes at higher doses. Overall, high interpatient variability in the $C_{\max }$ and AUC PK parameters was observed in these cohorts.

To date, five ALK inhibitors (crizotinib, ceritinib, alectinib, brigatinib and lorlatinib) have been approved by the US Food and Drug Administration for treatment of advanced NSCLC harbouring ALK aberrations. ${ }^{5}$ Approved ALK inhibitor formulations have less frequent dosing schedules than TSR-011 at Q8h. For example, alectinib and crizotinib are dosed BID and ceritinib is dosed QD. ${ }^{19}$ Therefore, the TSR-011 CR formulation was an attractive line of inquiry. In the formulation sub-study, after a single 30-mg CR dose of TSR-011, $C_{\max }$ and AUC values were lower than those observed with a single 30-mg IR dose of TSR-011. There was high interpatient variability in the $C_{\max }$ and AUC parameters. Nonparametric superposition projected that $240 \mathrm{mg}$ of this CR would have $C_{\text {trough }}$ of about $415.92 \mathrm{nmol} / \mathrm{L}$, which matches the $40 \mathrm{mg}$ IR TID cohort, with a $C_{\max }$ of about $693.20 \mathrm{nmol} / \mathrm{L}$, at which QTc prolongation is manageable.

At the RP2D, TSR-011 demonstrated clinical activity in the ALKpositive NSCLC subgroup that included both ALK inhibitor-naive patients and those previously treated with an ALK inhibitor. A higher response rate was observed in ALK inhibitor-naive patients (partial response rate, $42.9 \%$ vs $12.5 \%$, respectively). Stable disease occurred in eight ALK inhibitor-naive patients (57.1\%) and six patients previously treated with an ALK inhibitor (75.0\%). The observed efficacy of TSR-011 at the RP2D appears to be significantly less than that of other ALK inhibitors, which have shown an objective response rate of $>70 \%$ in a similar population. Similarly, an objective response rate of $12.5 \%$ is notably lower in the ALK pre-treated setting than what has been reported with all next-generation ALK inhibitors post crizotinib (55\%, ceritinib; $38-48 \%$, alectinib; $45-54 \%$, brigatinib; $48 \%$, lorlatinib). This was due to a suboptimal RP2D, which was limited by QTc prolongation. In preclinical studies, mice treated with an oral dose of TSR$01160 \mathrm{mg} / \mathrm{kg}$ showed complete ALK inhibition in Karpas-299 tumours at $8 \mathrm{~h}$, with a plasma concentration of $698.00 \mathrm{nmol} / \mathrm{L}$. Oral daily dosing of $60 \mathrm{mg} / \mathrm{kg}$ resulted in $>80 \%$ tumour growth inhibition, with an overall $24-\mathrm{h}$ exposure of $15,500 \mathrm{ng} \times \mathrm{h} / \mathrm{mL}$. A similar drug exposure for humans would require a daily dose ranging from 150 to $720 \mathrm{mg}$, based on the apparent clearance of 9.62-46.60 L/h. Exposure of the RP2D at $40 \mathrm{mg}$ TID (Q8h) (Fig. 1b) was lower than that of $120 \mathrm{mg}$ IR QD. The high interpatient variability of PK was not favourable for the further development of the compound.

In conclusion, dose escalation of TSR-011 in patients with relapsed or refractory cancers established the RP2D of $40 \mathrm{mg}$ TID (Q8h). QTc prolongation was a DLT with Q24h dosing at or above $320 \mathrm{mg}$. At the RP2D, TSR-011 had a favourable safety profile compared with most approved ALK inhibitors. Based on the competitive ALK inhibitor landscape and DLT of QTc prolongation, the development of TSR-011 has been discontinued.

\section{ACKNOWLEDGEMENTS}

We thank the patients and their families. Cindy Gomez, PhD (Ashfield Healthcare Communications, Middletown, CT, USA), drafted and revised the paper based on content and comments provided by the authors. Adrienne Schreiber of TESARO copyedited and styled the paper per journal requirements.

\section{AUTHOR CONTRIBUTIONS}

C.-C.L., H.-T.A., J.S, J.d.C.C., M.M., R.D., W.-C.S. and G.J.W. conducted the clinical study and provided the data. S.L., L.H., J.C. and Z.-Y.Z. analysed the data and provided the figures. D.B. and G.J.W. directed and coordinated the study and helped write the paper. 


\section{ADDITIONAL INFORMATION}

Supplementary information is available for this paper at https://doi.org/10.1038/ s41416-019-0503-9.

Competing interests: C.-C.L., H.-T.A., M.M. and W.-C.S. declare no conflict of interest. J.S. reports advisory board, consulting, travel support and grant funding for investigator-initiated trials from Celgene, drug support for investigator-initiated trials from Genentech, funding for investigator-initiated trials from Pfizer and advisory board and consulting fees from Taplmmune. J.d.C.C. reports advisory fees from AstraZeneca, Bristol-Myers Squibb, Merck Sharp \& Dohme, Novartis, Pfizer, Roche and Takeda. R.D. reports personal fees from AstraZeneca, Boehringer Ingelheim, BristolMyers Squibb, Novartis, Pfizer and Roche. G.J.W. reports ownership interest from Circulogene, personal fees from Circulogene, GLG Council, Guidepoint Global, IDEA Pharma, Ignyta, Paradigm, Pfizer, Angiex, Imaging Endpoints, Spring Bank Pharmaceuticals, and IBEX Medical Analytics, travel and lodging fees from Cambridge Healthtech Institute, GlaxoSmithKline, and TESARO, and holds a patent (PCT/US2014/ 8911940) outside the submitted work. S.L., D.B., L.H., J.C. and Z.-Y.Z. are employees and stockholders of TESARO: A GSK Company.

Ethics approval and consent to participate: This clinical investigation was conducted in compliance with Good Clinical Practice, the Declaration of Helsinki (version 2008) and other applicable regulatory requirements. The protocol was approved by the Institutional Review Board at each participating site (for a list of institutions see Table S2 of Supplemental Information, available at British Journal of Cancer website), and all patients provided written informed consent before study participation.

Funding: This clinical trial was funded by TESARO: A GSK Company Writing and editorial support were funded by TESARO and coordinated by Hemant Vyas, PhD, of TESARO.

Consent for publication: Not applicable.

Data availability: The data on internal records will be provided upon request

Publisher's note: Springer Nature remains neutral with regard to jurisdictional claims in published maps and institutional affiliations.

\section{REFERENCES}

1. Lin, J. J., Riely, G. J. \& Shaw, A. T. Targeting ALK: precision medicine takes on drug resistance. Cancer Discov. 7, 137-155 (2017).

2. Soda, M., Takada, S., Takeuchi, K., Choi, Y. L., Enomoto, M., Ueno, T. et al. A mouse model for EML4-ALK-positive lung cancer. Proc. Natl Acad. Sci. USA 105, 19893-19897 (2008).

3. Armstrong, F., Duplantier, M. M., Trempat, P., Hieblot, C., Lamant, L., Espinos, E. et al. Differential effects of X-ALK fusion proteins on proliferation, transformation, and invasion properties of NIH3T3 cells. Oncogene 23, 6071-6082 (2004).

4. Sasaki, T., Rodig, S. J., Chirieac, L. R. \& Jänne, P. A. The biology and treatment of EML4-ALK non-small cell lung cancer. Eur. J. Cancer 46, 1773-1780 (2010).

5. FDA CenterWatch. FDA Approved Drugs for Oncology. https://www.centerwatch. com/drug-information/fda-approved-drugs/therapeutic-area/12/oncology (accessed 25 Jan, 2019) (2019).
6. Solomon, B. J., Mok, T., Kim, D. W., Wu, Y. L., Nakagawa, K., Mekhail, T. et al. Firstline crizotinib versus chemotherapy in ALK-positive lung cancer. N. Engl. J. Med. 371, 2167-2177 (2014).

7. Davis, K. L., Kaye, J. A., Masters, E. T. \& lyer, S. Real-world outcomes in patients with ALK-positive non-small cell lung cancer treated with crizotinib. Curr. Oncol. 25, e40-e49 (2018).

8. Dagogo-Jack, I. \& Shaw, A. T. Crizotinib resistance: implications for therapeutic strategies. Ann. Oncol. 27, iii42-iii50 (2016).

9. Gainor, J. F., Dardaei, L., Yoda, S., Friboulet, L., Leshchiner, I., Katayama, R. et al. Molecular mechanisms of resistance to first- and second-generation ALK inhibitors in ALK-rearranged lung cancer. Cancer Discov. 6, 1118-1133 (2016).

10. Katayama, R., Khan, T. M., Benes, C., Lifshits, E., Ebi, H., Rivera, V. M. et al. Therapeutic strategies to overcome crizotinib resistance in non-small cell lung cancers harboring the fusion oncogene EML4-ALK. Proc. Natl Acad. Sci. USA 108, 7535-7540 (2011).

11. Peters, S. \& Zimmermann, S. Management of resistance to first-line anaplastic lymphoma kinase tyrosine kinase inhibitor therapy. Curr. Treat. Options Oncol. 19, 37 (2018).

12. Sullivan, I. \& Planchard, D. ALK inhibitors in non-small cell lung cancer: the latest evidence and developments. Ther. Adv. Med. Oncol. 8, 32-47 (2016).

13. Amatu, A., Sartore-Bianchi, A. \& Siena, S. NTRK gene fusions as novel targets of cancer therapy across multiple tumour types. ESMO Open 1, e000023 (2016).

14. Wilcoxen, K. M., Brake, R. L., Saffran, D., Teffera, Y., Choquette, D., Whittington, D. et al. Characterization of a novel series of potent, selective inhibitors of wild type and mutant/fusion anaplastic lymphoma kinase. Cancer Res. 72, 1795 (2012). (abstract 1795).

15. Holla, V. R., Elamin, Y. Y., Bailey, A. M., Johnson, A. M., Litzenburger, B. C., Khotskaya, Y. B. et al. ALK: a tyrosine kinase target for cancer therapy. Cold Spring Harb. Mol. Case Stud. 3, a001115 (2017).

16. Eisenhauer, E. A., Therasse, P., Bogaerts, J., Schwartz, L. H., Sargent, D., Ford, R. et al. New response evaluation criteria in solid tumours: Revised RECIST guideline (version 1.1). Eur. J. Cancer 45, 228-247 (2009).

17. ALECENSA (alectinib) [package insert] (Genentech USA, Inc., South San Francisco, CA, 2018).

18. ALUNBRIG (brigatinib) [package insert] (Takeda Pharmaceutical Company Limited, Cambridge, MA, 2018).

19. ZYKADIA (ceritinib) [package insert] (Novartis Pharmaceuticals Corporation, East Hanover, NJ, 2017).

Open Access This article is licensed under a Creative Commons Attribution 4.0 International License, which permits use, sharing, adaptation, distribution and reproduction in any medium or format, as long as you give appropriate credit to the original author(s) and the source, provide a link to the Creative Commons license, and indicate if changes were made. The images or other third party material in this article are included in the article's Creative Commons license, unless indicated otherwise in a credit line to the material. If material is not included in the article's Creative Commons license and your intended use is not permitted by statutory regulation or exceeds the permitted use, you will need to obtain permission directly from the copyright holder. To view a copy of this license, visit http://creativecommons. org/licenses/by/4.0/.

(c) The Author(s) 2019 